EMBRYARIDDLE
Aeronautical University

SCHOLARLY COMMONS

\section{International Journal of Aviation,} Aeronautics, and Aerospace

\title{
Ranking of Human Senses in Relation to Different In-flight Activities Contributing to the Comfort Experience of Airplane Passengers
}

Joyce Bouwens

Zodiac Seats US, j.m.a.bouwens@tudelft.nl

Suzanne Hiemstra-van Mastrigt

Delft University of Technology, S.Hiemstra-vanMastrigt@tudelft.nl

Peter Vink

Delft University of Technology, p.vink@tudelft.nl

Follow this and additional works at: https://commons.erau.edu/ijaaa

Part of the Aviation Commons, Environmental Design Commons, Ergonomics Commons, Industrial Engineering Commons, and the Interior Architecture Commons

\section{Scholarly Commons Citation}

Bouwens, J., Hiemstra-van Mastrigt, S., \& Vink, P. (2018). Ranking of Human Senses in Relation to Different In-flight Activities Contributing to the Comfort Experience of Airplane Passengers. International Journal of Aviation, Aeronautics, and Aerospace, 5(2). https://doi.org/10.15394/ijaaa.2018.1228

This Article is brought to you for free and open access by the Journals at Scholarly Commons. It has been accepted for inclusion in International Journal of Aviation, Aeronautics, and Aerospace by an authorized administrator of Scholarly Commons. For more information, please contact commons@erau.edu. 
When booking a flight, passengers seek comfort and are willing to pay higher prices in exchange for increased seat comfort (Airbus, 2013). A pleasant and comfortable experience also increases the likelihood that customers will return to an airline for future travel (Vink et al., 2012). Based on this, it makes sense for some airlines to invest in the design of a comfortable airplane interior. Many factors influence passengers' comfort, such as expectations and environment (De Looze et al., 2010; Vink \& Hallbeck, 2012). According to Krist (1993) and Bubb et al. (2015), comfort is established through six factors: anthropometry, climate, sound, vibrations, light and smell. These factors have been applied to airline travel in the following subsections.

\section{Literature Review}

\section{Anthropometry}

Anthropometry is the scientific study of measurements of the human body. When designing products such as aircraft seats, anthropometric data can be a valuable source of information. For instance, a study by Hiemstra-van Mastrigt (2015) comparing the dimensions of economy class aircraft seats to anthropometric measurements from a database demonstrated that current seats are not suitable for up to $21 \%$ of passengers due to the distance between armrests, which is too narrow to accommodate the hip width of some passengers. If the dimensions of the aircraft seat, such as width of the seat or the seat pitch (distance between two seats), are not well suited to the passenger, this will have an effect on the individual's perceived (dis)comfort.

\section{Climate}

Ranging from $20^{\circ} \mathrm{C}$ to $27^{\circ} \mathrm{C}$ on intercontinental flights and $21^{\circ} \mathrm{C}$ to $31.7^{\circ} \mathrm{C}$ on continental flights, the temperature in an airplane cabin varies significantly (Pang et al., 2014). A self-controlled heated and cooled office seat contributes to maintaining neutral body temperature, however the perceived comfort is higher when using a heated seat in a cold environment than when using a cooled seat in a warm environment, as suggested by Pasut (2013). Therefore, providing passengers with the right means to control their body temperature might contribute to a better comfort experience.

\section{Noise}

Aircraft interior sound levels depend on different factors, such as flying speed, altitude, and seat position (Quehl, 2001). The sound level (75 dB) inside an 
aircraft at cruise flight altitude (Ozcan \& Nemlioglu, 2006) mainly originates from the aircraft engines and does not cause permanent hearing loss (Mixson \& Powell, 1985) or reach the discomfort threshold (Slater, 1985). However, the noise levels in the aircraft cabin can result in annoyance (Mellert et al., 2008). Despite this, Quehl (2001) has suggested that annoyance caused by sound is based on individual preferences. Therefore, providing passengers with the right means to cancel or control the environmental noise (earplugs, noise cancelling headsets) might contribute to a better comfort experience.

\section{Vibrations}

Compared to other vehicles such as trains and cars, passengers in an aircraft at cruise flight altitude experience minor vibrations unless turbulence occurs. For instance, when passengers travel by train they experience significant lateral movement, which affects activities such as writing, eating and drinking (Bhiwapurkar \& Saran, 2010; Corbridge \& Griffin, 1991; Khan \& Sundstrom, 2007; Khan \& Sundström, 2004; Krishna Kant, 2007; Nassiri et al., 2011). In comparison, the vibrations experienced by most aircraft passengers are sufficiently minor that they do not affect most in-flight activities.

\section{Light}

Light and color are well-studied environmental factors that influence human beings. In the literature review by Sokolova and Fernández-Caballero (2015) it was found that color influences emotions and is applied in numerous fields (e.g. psychology, medicine, design and architecture). Although the authors indicated that there are global trends in color perception, the use of specific colors for different socio-demographic groups (i.e. cultures and ages) should be exercised with caution, since people might react differently to the same stimuli. For example, kids like the colors yellow and red, but when they grow older this preference will change to blue or green (Sokolova \& Fernández-Caballero, 2015). This should also be considered in the design of lighting in the airplane cabin, since the composition of passengers is diverse.

\section{Smell}

Majid and Kruspe (2018) found that hunter-gatherer tribes in the tropical rainforest of the Malay Peninsula could name odors as easy as colors. However, the reduced importance of recognizing smells in modern (and sedentary) life has led to a reduced ability to communicate about smell using words (Engen, 1982; Majid \& Kruspe, 2018). Despite its decreased importance, people do react to smell; odors 
can affect mood, physiology and behavior (Cardello \& Wise, 2008; Herz, 2009; Holland et al., 2005). Therefore, it is important to be aware of this when designing airplane cabin interiors.

Although many studies have been conducted focusing on individual factors, the relationship and hierarchy between different human senses remains underexamined in scientific literature. Research by Quehl (2001) on the effects of aircraft interior sound and vibration on passenger comfort demonstrated that the sound pressure level contributed to approximately $70 \%$ of the comfort evaluation while the vibration magnitude contributed to about $30 \%$. This was in line with the commonly reported dominance of noise in relation to subjective annoyance responses.

To indicate their relative significance, Bubb et al. (2015) proposed a generic hierarchical model of six discomfort sensations. In descending order, these are anthropometry, climate, sound, vibrations, light and smell. This model is established based on a study by Krist (1993). In this study participants were asked to indicate relevant factors that contribute to comfort experience. Anthropometry was mentioned most often by the interviewees, followed by climate, sound, vibration and light. Although smell was not mentioned by any of the participants, Bubb et al. (2015) suggested that smell must be a factor that contributes to comfort as well, because there is a direct connection between smell and the part of the brains that is responsible to emotion. Bubb et al. (2015) attributed the fact that smell is not mentioned by the participants to the unawareness of the participants, since they never experienced the effect of smell on comfort. Based on this, he suggested a hierarchical model, presented in a pyramid (see Figure 1). The base layer (smell) is most important, followed by other factors such as vibrations and climate. However, since the factors closer to the top of the pyramid were mentioned more often, Krist (1993) reasoned that it is less likely that these factors are accomplished yet.

In addition to this set of six environmental factors, more comfort factors have been described, such as expectations and time (Bazley, 2015). However, for the sake of manageable research not all factors influencing comfort are taken into account here, and only the influence of the six environmental factors smell, light, vibration, noise, climate and anthropometry are evaluated. The research question of this study is:

- What is the order of importance of the environmental factors as contributors to aircraft interior comfort experience, based on passenger expectations? 


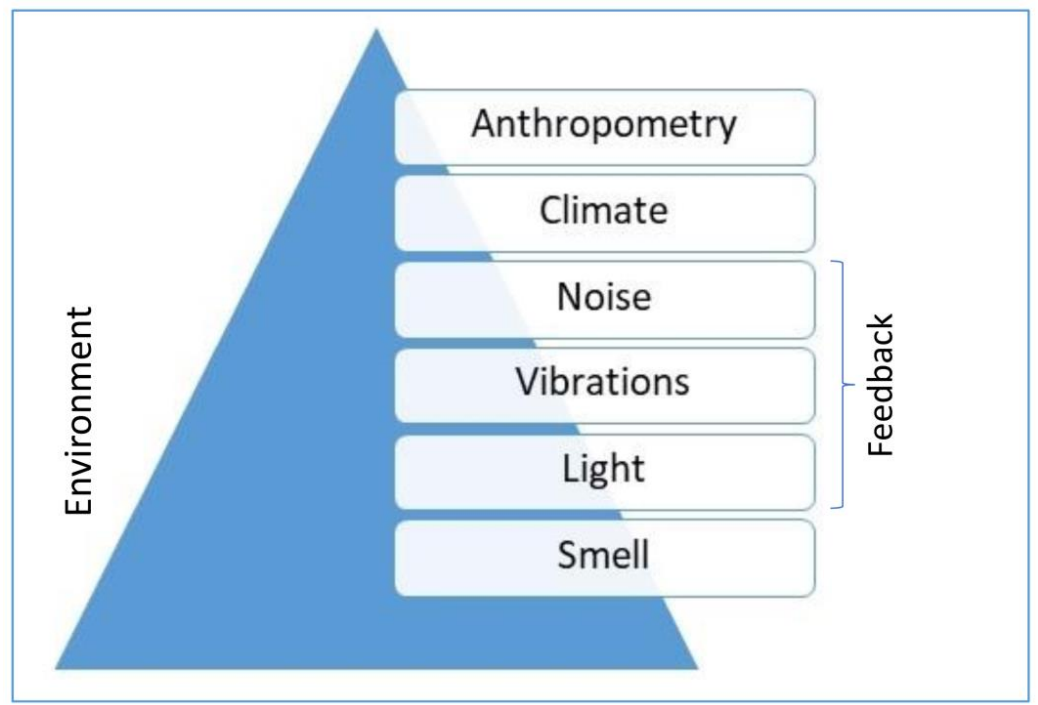

Figure 1. Hierarchy of environmental comfort factors represented in a pyramid (adapted from Bubb et al. (2015)). The environmental factors are ranked from most important (base of the pyramid) to least important (top of the pyramid).

\section{Study 1: Evaluation of Environmental Factors}

\section{Method}

In a questionnaire, respondents were asked to rank six different human senses: climate, vibration, light, noise, anthropometry and smell. These senses were presented to participants as 15 different "word pairs," and respondents were asked which element, according to their expectations, is the most important in experiencing a comfortable aircraft interior. For each of the environmental element pairs (Table 1) participants were asked to indicate which factor was more valuable to them. Respondents were recruited at the faculty of Industrial Design Engineering at Delft University of Technology. In total, 183 respondents between 19 and 64 years old (mean: 30.5, SD: 12.8), of which were 114 female and 66 were male (3 unknown), with flight experience completed the questionnaire. The scores for each environmental factor were analyzed with a Friedman test utilizing IBM SPSS Statistics 24, and significance was accepted at $p<0.05$. When significance was found, a Wilcoxon signed rank test utilizing BM SPSS Statistics 24 was used to determine between which elements differences occurred. For the Wilcoxon signed rank test significance was accepted at $p<0.05$. Additionally, respondents were allowed to provide comments on the questionnaire. 
Table 1

Environmental factors (each factor occurs five times)

\begin{tabular}{|ll|}
\hline Element 1 & Element $\mathbf{2}$ \\
\hline Climate & Noise \\
\hline Vibration & Light \\
\hline Light & Climate \\
\hline Noise & Light \\
\hline Anthropometry & Smell \\
\hline Smell & Climate \\
\hline Vibration & Anthropometry \\
\hline Light & Anthropometry \\
\hline Noise & Vibration \\
\hline Vibration & Smell \\
\hline Noise & Smell \\
\hline Anthropometry & Noise \\
\hline Climate & Vibration \\
\hline Smell & Light \\
\hline Anthropometry & Climate \\
\hline
\end{tabular}

\section{Results}

The Friedman test found a statistically significant difference between the environmental factors, $\chi 2(5, N=183)=193.43, p<0.001$. Post hoc analysis with Wilcoxon signed-rank tests was conducted with a Bonferroni correction applied, resulting in a significance level set at $p<0.01$. The average importance of anthropometry was $3.46(S D=1.54)$, noise $2.91(S D=1.38)$, smell $2.91(S D=$ 1.65), climate $2.69(S D=1.50)$, and vibrations $1.91(S D=1.50)$, and light $1.11(S D$ $=1.2)$. There were no significant differences between noise and smell $(Z=-.022, \mathrm{p}$ $=0.982)$ and smell and climate $(Z=-1.238, p=0.216)$. However, there were significant differences between anthropometrics and noise $(Z=-.3220, p=0.001)$, climate and vibrations $(Z=-4.583, p<0.001)$, and vibrations and light $(Z=-$ 5.002, $p<0.001$ ) (see Figure 2).

The element of anthropometry was, on average, indicated between 3 and 5 times as more important for experiencing aircraft interior comfort. The three elements of noise, smell and climate were indicated as more important approximately 3 times, the element of vibration twice and the element light just once. Three significant differences were found between anthropometry and noise, smell and climate, climate and vibrations and vibrations and light. 


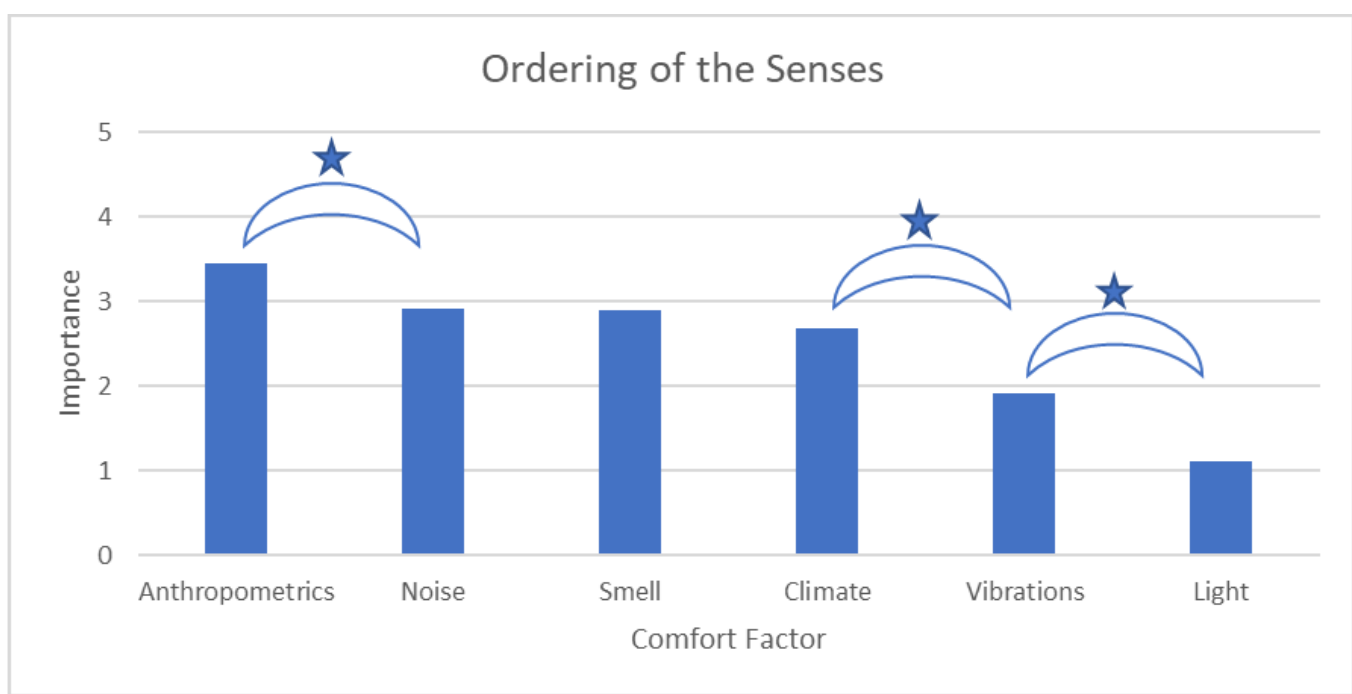

Figure 2. Ordering of the human senses from most important (5) to least important $(0)$ for experiencing aircraft interior comfort $(n=183$, the asterisk $*$ indicates significance $\mathrm{p}<0.05)$.

In $16 \%$ of the comments by respondents it was mentioned that their choice of most important factor is dependent on the situation. For example, one of the comments on climate stated, "Does climate refer to warm or cold air?" With regard to smell, one participant commented, "I hate a bad smell more than I love a nice smell."

\section{Discussion}

This study illustrates that it is possible to create a hierarchy of environmental factors related to expected impact on comfort experience. The respondents indicated anthropometry as the most important factor, followed by noise, smell, climate, vibrations and finally light. This order differs from the discomfort pyramid proposed by Krist (1993) and Bubb et al. (2015). However, the respondents stated that the context of the factors was unclear, since the importance of each factor might depend on the performed in-flight activity (e.g. "I prefer a different temperature while sleeping than while walking"). Moreover, the factors were insufficiently explained (e.g. "Does climate refer to warm or cold air?"). Therefore, in order to provide reliable results, this study required repetition with a questionnaire that was clear and unequivocal, and which clarified context by adding an in-flight activity. 


\section{Study 2: Evaluation of Environmental Factors in Relation to In-flight Activities}

The study described in Section 2 of this article was repeated after improving the research design based on the feedback from respondents.

\section{Method}

In a questionnaire, respondents were asked to rank six environmental factors of an airplane cabin for two activities, namely sleeping and watching the in-flight entertainment (IFE) screen. A general explanation of each factor was provided as follows:

- Seat: Adjustable seat to match personal body measurements

- Temperature: Manipulate temperature to personal preference

- Noise: Possibility to reduce cabin noise

- Vibrations: Control vibrations caused by the airplane

- Light: Control the intensity and color of the light

- Smell: Possibility to reduce bad odors in the airplane cabin

These senses were presented as 15 different "word pairs," and respondents were asked which factor, according to their expectations, is the most important in experiencing a comfortable aircraft interior for two different activities, sleeping or watching IFE. The survey was completed 168 times by respondents that did not participate in the first study. Respondents were recruited at the faculty of Industrial Design Engineering at Delft University of Technology. One response was not evaluated because the participant indicated that he did not have flight experience. The other 167 respondents were between 19 and 61 years old (mean: 26.6, SD: 9.0), of which were 98 female and 69 were male. The number of times each element was indicated as more important was recorded for each activity, and these scores were analyzed with a Friedman test (IBM SPSS Statistics 24). Significance was accepted at $\mathrm{p}<0.05$. When significance was found, a Wilcoxon signed rank test (IBM SPSS Statistics 24) was used to determine where differences occurred between elements. For the Wilcoxon signed rank test significance was accepted at $\mathrm{p}<0.05$.

\section{Results}

Figure 3 and Figure 4 show the ranking of comfort aspects when sleeping and watching IFE. 
There was a statistically significant difference in importance of each environmental factor, $\chi 2(5, N=167)=263.00, p<0.001$ for the activity sleeping. Post hoc analysis with Wilcoxon signed-rank tests was conducted with a Bonferroni correction applied, resulting in a significance level set at $p<0.01$. The average importance of the seat was $4.09(S D=1.07)$, noise $2.86(S D=1.29)$, temperature $2.80(S D=1.38)$, light $2.01(S D=1.34)$, vibrations $1.31(S D=1.41)$, and smell $1.69(S D=1.60)$. There were no significant differences between noise and temperature $(Z=-0.464, p=0.643)$, light and smell $(Z=-1.628, p=0.104)$ and smell and vibrations $(Z=-1.961, p=0.050)$. However, there were significant differences between the seat and noise $(Z=-7.135, p<0.001)$, and temperature and light $(Z=-4.451, p=0.643)$.

For the activity watching IFE, a significant difference in importance of each environmental factor was found, $\chi 2(5, N=167)=219.04, p<0.001$. Post hoc analysis with Wilcoxon signed-rank tests was conducted with a Bonferroni correction applied, resulting in a significance level set at $p<0.01$. The average importance of the seat was $3.65(S D=1.12)$, noise $3.43(S D=1.42)$, temperature $1.87(S D=1.37)$, light $2.47(S D=1.16)$, vibrations $1.80(S D=1.61)$, smell 1.45 $(S D=1.64)$. There were no significant differences between the seat and noise $(Z=$ $-1.374, p=0.170)$ temperature and vibrations $(Z=-0.523, p=0.601)$, and vibrations and smell $(Z=-1.788, p=0.074)$. However, there were significant differences between noise and light $(Z=-6.065, p<0.001)$, and light and temperature $(Z=$ $-3.577, p<0.001)$.

The results for IFE and sleeping appear rather similar, except for temperature and light. Temperature was found to be more important than light for sleeping, while light was ranked as more important for IFE than temperature.

\section{Discussion}

The results of the second study suggest that for the in-flight activities of watching IFE and sleeping, airplane passengers consider different human senses important (see Figure 5). Nevertheless, the seat (anthropometrics) is considered the most important factor for both activities. The first study shows anthropometry as the most important factor, noise as falling in the mid-range and vibration in the top, least important area. However, other factors appear to take different positions within the comfort pyramid. Therefore, it is possible that the way a factor is interpreted plays a role in the score it receives. The absence of light while sleeping has a different effect than watching a movie in the dark. 


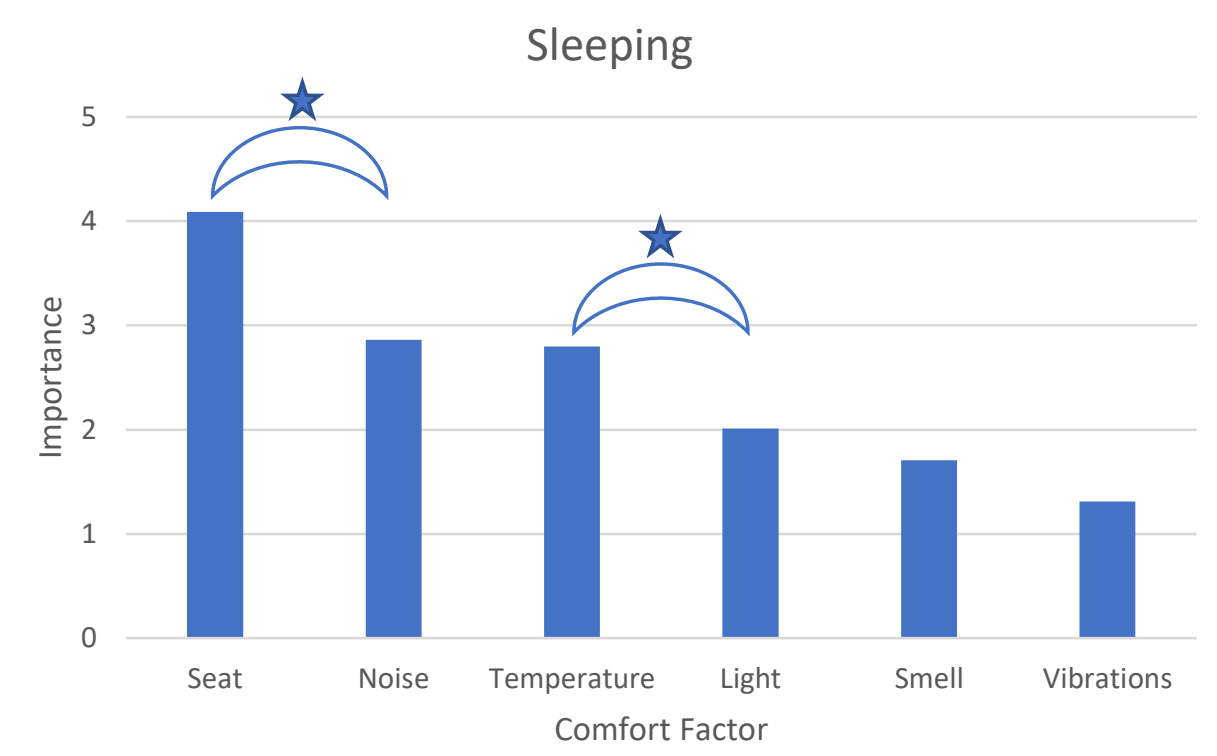

Figure 3. Ordering of the human senses from most important (5) to least important $(0)$ for experiencing aircraft interior comfort while sleeping $(n=167$, the asterisk $*$ indicates significance $\mathrm{p}<0.05)$.

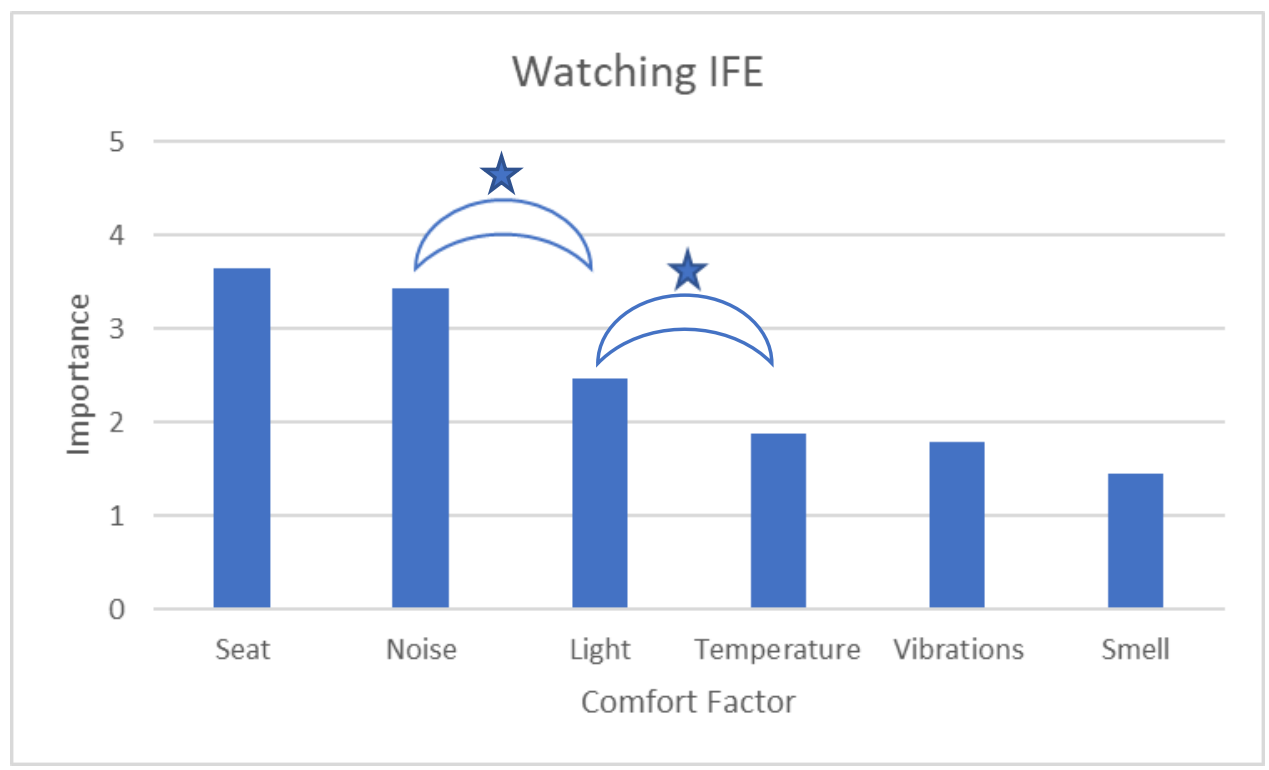

Figure 4. Ordering of the human senses from most important (5) to least important (0) for experiencing aircraft interior comfort while watching IFE ( $\mathrm{n}=$ 167 , the asterisk $*$ indicates significance $\mathrm{p}<0.05)$. 


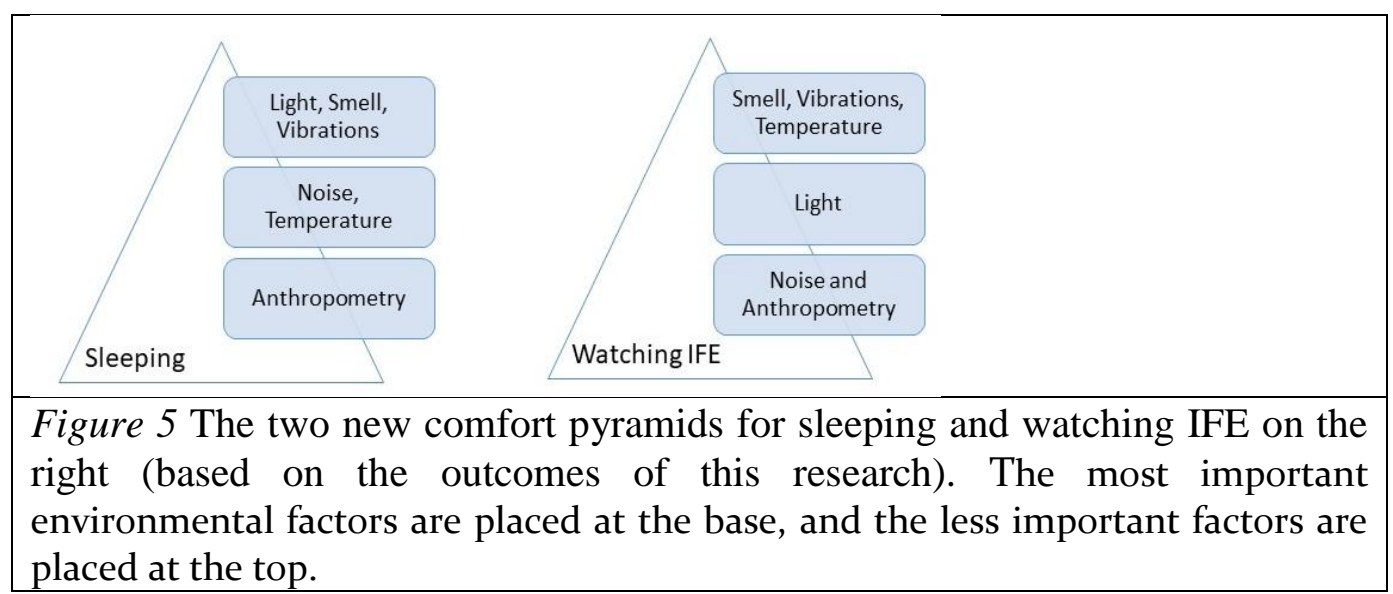

Anthropometry's importance is also seen in other studies. Kuijt-Evers (2007), for instance, demonstrated in hand tool research that while working with a screwdriver, the appearance of the tool (related to visual system) has almost no influence on comfort while the anthropometry (tool fit to the hand) has a strong influence.

There are some similarities between the findings of Krist (1993) and Bubb et al. (2015), since anthropometry is mentioned most in both studies. However, the position of this factor in the pyramids is different. Expectations and emotions influence passenger comfort (Ahmadpour et al., 2014; De Looze et al., 2010; Vink \& Hallbeck, 2012), and might have influenced this order. For example, since passengers expect to have limited personal space in the airplane seat, they consider this aspect much more important than light or smell (since they have never experienced problems with these factors in the past). Also, passengers are not always aware of the influence of some of the environmental factors. For instance, noise does affect the human comfort experience unconsciously. A study by Mellert et al. (2008) found, for example, that more physical complaints were reported in a noisy airplane cabin. Similarly, the design of the airplane cabin ceiling affects the perceived seat comfort, air quality and temperature (McMullin, 2013). Therefore, passengers might consider some factors less important when in fact these factors have a considerable effect on actual comfort experience.

Although the outcomes of this research suggest a hierarchical order of factors that might give direction to prioritizing design efforts, Vink et al. (2016) discuss that optimizing every single element in the environment in order to optimize comfort is neither possible nor wise. Lewis et al. (2016) suggest that people can be distracted from sources of discomfort by a virtual environment. This technique 
appears to be more effective for distracting people from discomfort caused by restricted space than noise disturbances (such as a crying baby). Although rather counterintuitive, negative associations people might have with certain factors, such as noise, can also have positive side effects. For example, the presence of background noise is considered positive by train riders, as it masks other sounds like conversations between other passengers (Khan, 2003).

In the second questionnaire the environmental factors were clarified by providing definitions. Even though this was a major improvement on the initial questionnaire, respondents may still have interpreted the definitions differently (e.g. adjustable seat to match personal body measurements might refer to the adjustability of the width and/or the recline function). Therefore, more research is needed in order to define design requirements for each environmental factor that lead to an improved comfort experience. Future research is also needed to quantify the relationships between different factors of the comfort pyramid, and to research the generalizability of the outcomes to other fields (e.g. comfort of offices, car interiors).

\section{Conclusion}

This study indicates that different in-flight activities require different environmental properties in order to facilitate passengers' comfort during their flight. The results from the second study $(n=167)$ suggest that a hierarchy of any comfort-related environmental factors depends on the performed in-flight activity. 


\section{References}

Ahmadpour, N., Lindgaard, G., Robert, J. M., \& Pownall, B. (2014). The thematic structure of passenger comfort experience and its relationship to the context features in the aircraft cabin. Ergonomics, 57(6), 801-815. doi: $10.1080 / 00140139.2014 .899632$

Airbus. (2013). Passengers willing to invest time and money in search of comfort. Retrieved from http://www.airbus.com/presscentre/pressreleases/pressrelease-detail/detail/passengers-willing-to-invest-time-and-money-insearch-of-comfort/

Bazley, C. (2015). Beyond comfort in built environments. (Doctoral dissertation). Retrieved from Repository Delft University of Technology.

Bhiwapurkar, M., \& Saran, V. (2010). Effect of multi axis vibration and subject postures on sketching distortion. International Journal of Engineering, Science and Technology, 2(12), 12-24.

Bubb, H., Bengler, K., Grünen, R., \& Vollrath, M. (2015). Automobilergonomie. Wiesbaden, Germany: Springer Vieweg.

Cardello, A., \& Wise, P. (2008). Taste, smell and chemesthesis in product experience. In H. N. Schifferstein \& P. Hekkert (Eds.), Product experience (pp. 91-131). Amsterdam, Netherlands: Elsevier.

Corbridge, C., \& Griffin, M. J. (1991). Effects of vertical vibration on passenger activities: writing and drinking. Ergonomics, 34(10), 1313-1332. doi: 10.1080/00140139108964870

De Looze, M. P., Kuijt-Evers, L. F. M., \& Van Dieën, J. (2010). Sitting comfort and discomfort and the relationships with objective measures. Ergonomics, 46(10), 985-997. DOI: 10.1080/0014013031000121977

Engen, T. (1982). The perception of odors. New York, NY: Academic Press.

Herz, R. S. (2009). Aromatherapy facts and fictions: a scientific analysis of olfactory effects on mood, physiology and behavior. International Journal of Neuroscience, 119(2), 263-290. doi: 10.1080/00207450802333953 
Hiemstra-van Mastrigt, S. (2015). Comfortable passenger seats: Recommendations for design and research (Doctoral dissertation). Retrieved from Repository Delft University of Technology.

Holland, R. W., Hendriks, M., \& Aarts, H. (2005). Smells like clean spirit: Nonconscious effects of scent on cognition and behavior. Psychological Science, 16(9), 689-693. DOI: 10.1111/j.1467-9280.2005.01597.x

Khan, M. S., \& Sundstrom, J. (2007). Effects of vibration on sedentary activities in passenger trains. Journal of Low Frequency Noise, Vibration and Active Control, 26(1), 43-55. DOI: 10.1260/026309207781487448

Khan, S. (2003). Effects of masking sound on train passenger aboard activities and on other interior annoying noises. Acta Acustica united with Acustica, $89,711-717$.

Khan, S., \& Sundström, J. (2004). Vibration comfort in Swedish Inter-City trains-a survey on passenger posture and activities. Proceedings of the 17th International Conference in Acoustics (pp. 3733-3736), Kyoto, Japan.

Krishna Kant, P. V. (2007). Evaluation of Ride and Activity Comfort for the Passengers While Travelling by Rail Vehicles. (Master Thesis), Indian Institute of Technology Roorkee

Krist, R. (1993). Modellierung des Sitzkomforts - eine experimentelle Studie. (Doctoral dissertation), Katholischen Universität Eichstätt, Eichstätt, Germany.

Kuijt-Evers, L. F. M. (2007). Comfort in using hand tools: theory, design and evaluation. (Doctoral dissertation). Retrieved from Repository Delft University of Technology.

Lewis, L., Patel, H., Cobb, S., D’Cruz, M., Bues, M., Stefani, O., \& Grobler, T. (2016). Distracting people from sources of discomfort in a simulated aircraft environment. Work, 54(4), 963-979.

Majid, A., \& Kruspe, N. (2018). Hunter-Gatherer Olfaction Is Special. Current Biology, 28, 409-413. doi:10.1016/j.cub.2017.12.014 
McMullin, D. (2013). Aircraft seating comfort in the context of passenger comfort. Presentation at the IQPC Innovative Aircraft Seating conference, Hamburg, Germany.

Mellert, V., Baumann, I., Freese, N., \& Weber, R. (2008). Impact of sound and vibration on health, travel comfort and performance of flight attendants and pilots. Aerospace Science and Technology, 12(1), 18-25.

Mixson, J. S., \& Powell, C. A. (1985). Review of recent research on interior noise of propeller aircraft. Journal of aircraft, 22(11), 931-949.

Nassiri, P., Koohpaei, A., Zeraati, H., \& Shalkouhi, P. J. (2011). Train Passengers Comfort with regard to Whole-Body Vibration. Journal of Low Frequency Noise, Vibration and Active Control, 30(2), 125-136.

Ozcan, H. K., \& Nemlioglu, S. (2006). In-cabin noise levels during commercial aircraft flights. Canadian Acoustics, 34(4), 31-35.

Pang, L., Qin, Y., Liu, D., \& Liu, M. (2014). Thermal comfort assessment in civil aircraft cabins. Chinese Journal of Aeronautics, 27(2), 210-216.

Pasut, W., Zhang, H., Arens, E., Kaam, S., \& Zhai, Y. (2013). Effect of a heated and cooled office chair on thermal comfort. HVAC\&R Research, 19(5), 574-583.

Quehl, J. (2001). Comfort studies on aircraft interior sound and vibration. (Doctoral dissertation). Retrieved from Repository Universität Oldenburg.

Slater, K. (1985). Human comfort (Vol. 1): Springfield, IL: Thomas.

Sokolova, M. V., \& Fernández-Caballero, A. (2015). A review on the role of color and light in affective computing. Applied Sciences, 5(3), 275-293.

Vink, P., Bazley, C., \& Jacobs, K. (2016). Modeling the relationship between the environment and human experiences. Work, 54(4), 765-771.

Vink, P., Bazley, C., Kamp, I., \& Blok, M. (2012). Possibilities to improve the aircraft interior comfort experience. Applied Ergonomics, 43(2), 354-359.

Vink, P., \& Hallbeck, S. (2012). Editorial: Comfort and discomfort studies demonstrate the need for a new model. Applied Ergonomics, 43(2), 271 276. doi:http://dx.doi.org/10.1016/j.apergo.2011.06.001 